EXTENDED REPORT

\title{
Intracellular and extracellular CPPD crystals are a regular feature in synovial fluid from uninflamed joints of patients with CPPD related arthropathy
}

\author{
A Martínez Sanchis, E Pascual
}

See end of article for authors' affiliations

.....................

Correspondence to: Dr Agustin Martínez Sanchis, Calle Pintor Baeza, s/n Alicante 03010, Spain; martinez_agu@gra.es

Accepted 14 May 2005

Published Online First

7 June 2005

\begin{abstract}
Objectives: To determine whether calcium pyrophosphate dihydrate (CPPD) crystals can be found in the synovial fluid of non-inflamed joints in patients with CPPD related arthropathy; if so, to determine whether they interact with cells and produce subclinical inflammation in this setting.

Methods: 74 synovial fluid samples were obtained from non-inflamed knees of 74 patients with CPPD related arthropathy. Identification of CPPD crystals and synovial fluid cell counts were done manually in undiluted samples using a haematocytometric chamber. A supravital stain (Testsimplets, Boehringer Mannheim) was used to carry out differential counts and to assess the presence of intracellular crystals. Results: All 74 samples contained CPPD crystals. The mean cell count was 301.4 cells $/ \mu$ l $(95 \%$ confidence interval (Cl), 216.6 to 386.4 ; range 22 to 2302.5$)$. Mononuclear cells accounted for $83.2 \%(95 \% \mathrm{Cl}$, $80.4 \%$ to $86.1 \%$; range $43 \%$ to $99 \%$ ), the rest being polymorphonuclear (PMN) cells $(16.8 \%(95 \% \mathrm{Cl}$, $13.9 \%$ to $19.6 \%$; range $1 \%$ to $57 \%)$. All the samples contained intracellular CPPD crystals, which were found in $24.0 \%$ of all the cells $(95 \% \mathrm{Cl}, 20.1 \%$ to $27.9 \%$; range $1 \%$ to $78 \%)$. Most of the intracellular crystals were inside mononuclear cells $(22.2 \%$ of all the cells $(95 \% \mathrm{Cl}, \mathrm{Cl} 18.5 \%$ to $25.9 \%))$, although some PMN also contained them (1.8\% of all the cells $(95 \% \mathrm{Cl}, 1.1 \%$ to $2.4 \%)$ ).

Conclusions: CPPD crystals are normally found in synovial fluid of non-inflamed joints of patients with CPPD related arthropathy, and they interact with cells. The raised cell counts and percentage of PMN suggest mild subclinical inflammation in these joints.
\end{abstract}

C alcium pyrophosphate dihydrate (CPPD) crystal related arthropathy is characterised by the presence of these crystals in synovial fluid samples obtained from the joints of the patients at the time of inflammation. ${ }^{1}$ Clinical features include acute episodes of self limited arthritis (which have been known as pseudogout), and a chronic degenerative arthropathy that resembles osteoarthritis). ${ }^{2}{ }^{3}$

The presence of CPPD crystals in the joint cavity appears as an essential factor for the induction of joint inflammation. CPPD crystals are found in the synovial fluid of patients during acute attacks. Injection of the crystals in canine joints induces an acute inflammatory response. ${ }^{45}$ In vitro exposure of monocytes, synoviocytes, and human neutrophils to CPPD crystals results in release of proinflammatory and chemotactic mediators. ${ }^{6-10}$ According to this model, which closely links presence of CPPD crystals to inflammation, the joints would be free of such crystals outside the periods of clinical inflammation.

In gout, monosodium urate (MSU) crystals stay in the joint and are always found in the synovial fluid after they form, provided that patients have not received a sufficient period of hypouricaemic treatment. ${ }^{11}{ }^{12}$ Moreover, in asymptomatic joints MSU crystals are actively phagocytosed ${ }^{13}$ and are associated with slightly raised cell counts and increased percentages of polymorphonuclear (PMN) leucocytes, suggesting the presence of mild subclinical inflammation. ${ }^{14}{ }^{15}$

Our aim in this study was to determine whether CPPD crystals behave similarly to MSU crystals in gout. Thus we have tried to establish first, whether CPPD crystals are found in synovial fluid samples from non-inflamed knees of patients with known CPPD related arthropathy; second, whether phagocytosis of the crystals occurs in this setting; and third, whether cell count and the percentage of PMN cells in the same synovial fluid samples are higher than normal, indicating some degree of subclinical inflammation in these asymptomatic joints. As an additional objective, we tried to determine whether synovial fluid samples from patients with pain showed any difference in the presence of crystals, cellularity, percentage of PMN, and crystal phagocytosis, which could link pain with mild inflammation caused by CPPD crystals.

\section{METHODS}

\section{Patients}

Initially, 92 patients with CPPD related arthropathy were invited to enter the study. In every patient, the diagnosis had been established previously by identification of CPPD crystals in a synovial fluid sample. Seventy nine of them agreed, and informed consent was obtained from each. At the time that synovial fluid samples were obtained, all these patients fulfilled the following criteria:

- The time interval between the diagnostic arthrocentesis, and the sampling for the study was two months or longer.

- For study purpose, presence of joint inflammation was defined as a combination of pain, swelling caused by the presence of an effusion, with some restriction of motility, and the observation of over 2000 cells/ $\mu \mathrm{l}$ in the synovial fluid. For all the patients studied, current joint inflammation was absent at the time of the study; however, it was accepted that some patients could have stable mild pain, or a small joint effusion, detectable by a positive bulge sign. Finally, it was required that patients had been free of

Abbreviations: CPPD, calcium pyrophosphate dihydrate; MSU, monosodium urate; NSAID, non-steroidal anti-inflammatory drugs; PMN, polymorphonuclear neutrophil white blood cells 


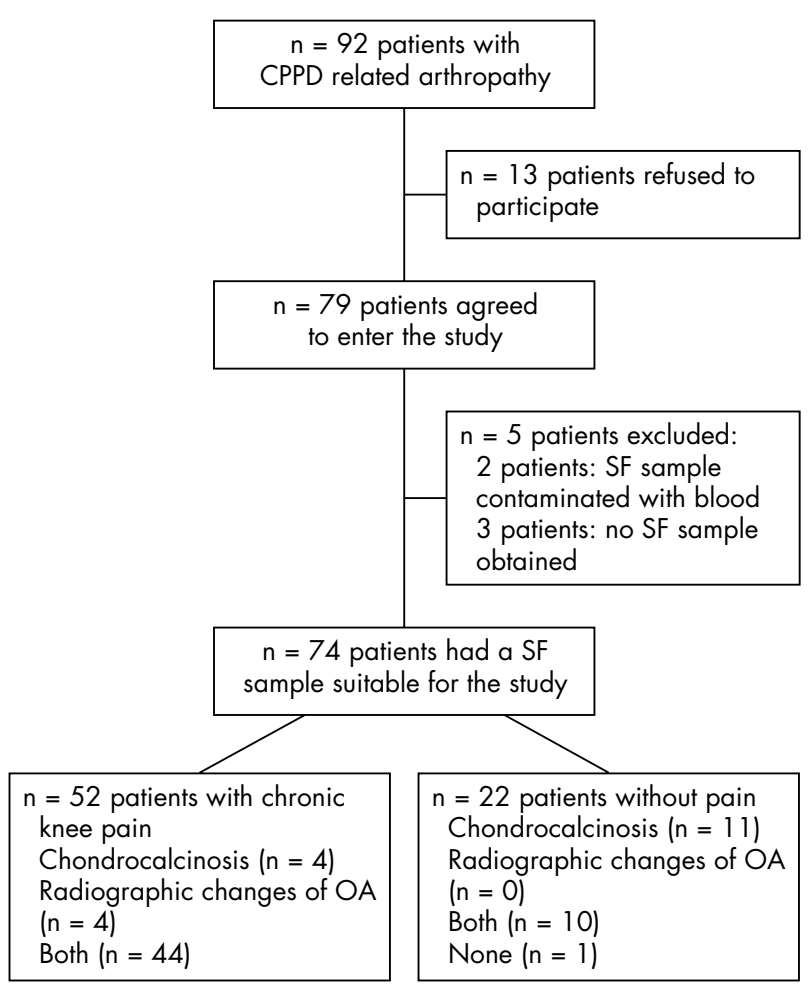

Figure 1 Classification of the patients.

joint inflammation or relevant increase in knee pain in the two months prior to the study.

- Patients had been off colchicine or non-steroidal antiinflammatory drugs (NSAIDs) for at least two months (acetaminophen was allowed for pain).

Radiological assessment was carried out by using standing fully extended anteroposterior and $30^{\circ}$ flexion lateral views of the knee studied, to evaluate the presence of signs of osteoarthritis (joint space narrowing, osteophytes, or both), and radiological chondrocalcinosis.

After assessment, knee arthrocentesis was carried out. Seventy four synovial fluid samples, obtained from 74 patients, were suitable for the study. Five patients were excluded, as two samples from two patients were contaminated with blood (and found not suitable for the study), and no fluid was obtained in other three patients. Thus 74 patients were finally included. Patients were classified according to the presence of pain into two groups: those with chronic knee pain $(\mathrm{n}=52)$ and those without $(\mathrm{n}=22)$ (fig 1). In the group of patients with pain, radiographic chondrocalcinosis, radiographic changes of osteoarthritis, or both were observed in 4, 4, and 44 patients, respectively; in the group without pain, these findings were seen in 11,0 , and 12 patients, respectively; one patient's radiograph did not show either chondrocalcinosis or radiographic changes of osteoarthritis.

With respect to previous joint inflammation, 33 patients had experienced previous pseudogout crises ( 23 in the knee, 10 in other joints). Joint inflammation had occurred in 20 of 52 patients in the group with chronic knee pain, and in 13 of 22 patients in the group without pain. Diagnostic arthrocentesis had been carried out at that time, and the mean time interval between resolution of inflammation and obtaining synovial fluid samples for the study was 11.9 months $(95 \%$ confidence interval (CI), 6.3 to 17.4; range 2 to 60 ). In the 41 patients who did not have previous joint inflammation, the

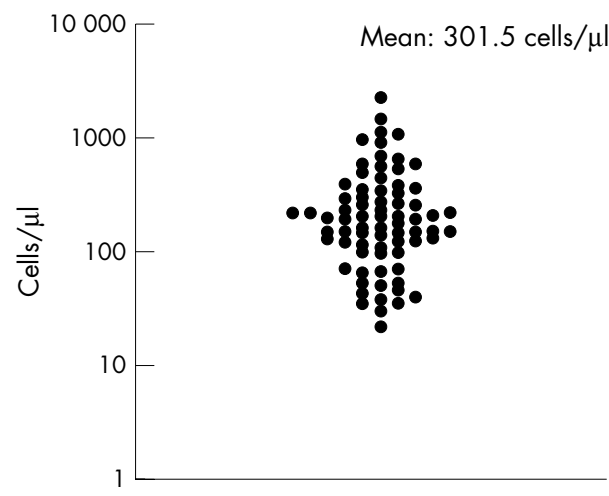

Figure 2 Cell counts in the 74 patients.

synovial fluid samples for the study were obtained two months after the diagnostic arthrocentesis had been performed.

\section{Synovial fluid samples}

Knee arthrocentesis was undertaken by a medial retropatellar approach, using a $1 \mathrm{ml}$ plastic syringe and a 21 gauge needle, after routine aseptic precautions. Synovial fluid analysis was done immediately after extraction. Cell counts were carried out manually in undiluted synovial fluid, using a Neubauer haemocytometric chamber, as previously described. The same preparation was used to identify CPPD crystals: as most CPPD crystals are not birefringent, ${ }^{16}$ crystal detection was carried out by means of an ordinary microscope, and identification confirmed with a polarised light microscope provided with a first order red compensator. ${ }^{17}$ No other calcium crystals were sought in this study. Poor reproducibility has been reported for crystal identification in synovial fluid. ${ }^{18-20}$ However, reproducibility is related to the training of the observers, as we have found that after training crystal detection and identification is consistent. In our study, the investigator (AMS) who carried out the synovial fluid analysis has long experience in crystal detection and identification of CPPD crystals, and his margin of error is likely to be small.

Differential cell counts were done using pre-stained slides (Testsimplets, Boehringer Mannheim, Germany). ${ }^{21}$ CPPD crystals were searched for in every cell and the percentage of cells with intracellular crystals was noted, as supravital staining with Testsimplets does not modify the morphology and optic characteristics of the crystals.

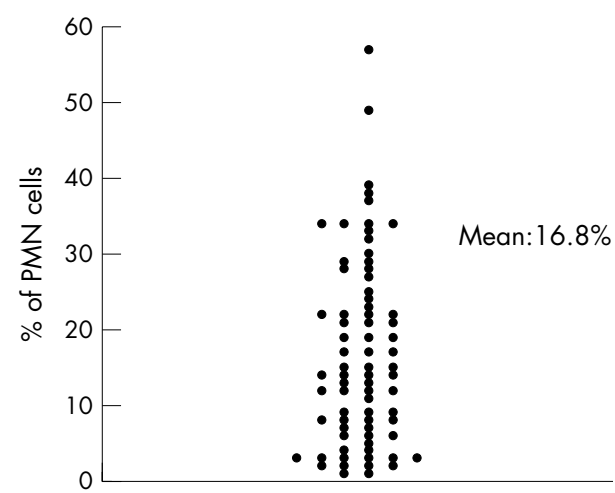

Figure 3 Percentage of polymorphonuclear (PMN) cells. 


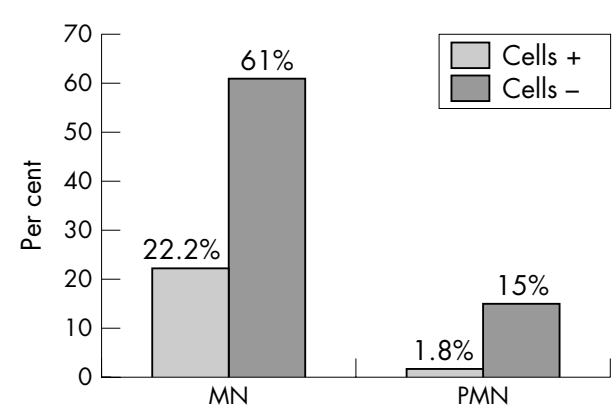

Figure 4 Percentage of mononuclear $(M N)$ and polymorphonuclear (PMN) cells, with $(+)$ without $(-)$ intracellular crystals.

\section{Statistical analysis}

The mean, 95\% CI for the mean, and range were calculated for all the counts made. Statistical analysis was carried out using the non-parametric rank sum test, also known as the Mann-Whitney-Wilcoxon test for non-parametric independent samples, to compare cell counts, PMN cell percentages, and percentages of cells with intracellular crystals, as the number of patients was rather small and distributions were not normal.

\section{RESULTS}

Of the 74 patients studied, 27 were men and 47 women (male to female ratio 0.57 ). Their mean age was 68.3 years ( $95 \%$ CI, 65.8 to 70.7; range 40 to 90 ). All 74 synovial fluid samples contained CPPD crystals. The mean cell count was 301.5 cells $/ \mu$ l (95\% CI, 216.6 to 386.4 ; range 22 to 2302.5 ) (fig 1). Mononuclear cells accounted for $83.2 \%$ (95\% CI, 80.4 to 86.1 ; range 43 to 99 ), the remaining $16.8 \%$ being PMN (95\% CI, 13.9 to 19.6; range 1 to 57 ). PMN cells were observed in all 74 samples (fig 2). Cells with intracellular CPPD crystals were observed in all 74 samples. The mean percentage of cells containing crystals was $24.0 \%$ (95\% CI, 20.1 to 27.9 ; range 1 to 78 ); most of these were mononuclear cells $(22.2 \% ; 95 \% \mathrm{CI}, 18.5$ to 25.9 ; range 1 to 78$)$, though some PMN also showed intracellular crystals (1.8\%; 95\% CI, 1.1 to 2.4; range 0 to 15 ) (fig 3). The cells that contained crystals often contained more than one crystal.

In the group of patients with chronic knee pain (pain group), the mean proportion of cells with intracellular CPPD crystals was $23.7 \%$ (95\% CI, 19.3 to 28.0 ; range 1 to 59 ), and $24.7 \%$ (95\% CI, 16.0 to 33.4; range 2 to 78 ) in the group of patients without pain (asymptomatic group) ( $p=0.93$, NS). The mean cell count in the pain group was 338.1 cells/ $\mu \mathrm{l}(95 \%$ CI, 225.8 to 450.3 ; range 22 to 2302.5 ), and in the asymptomatic group, 215.0 cells/ $\mu \mathrm{l}$ (95\% CI, 105.8 to 324.2 ; range 30 to 1130$)(p=0.07$, NS). PMN cells accounted for a mean of $17.5 \%$ of cells in the pain group (95\% CI, 14.2 to 20.9; range 1 to 57 ), and for $15.0 \%$ in the asymptomatic group (95\% CI, 9.3 to 20.6; range 1 to 39$)(p=0.28$, NS). The results are summarised in table 1 .

\section{DISCUSSION}

We studied 74 synovial fluid samples from non-inflamed knees of patients with CPPD related arthropathy, and found CPPD crystals in all of them. This indicates that they are regularly present in the joint cavity of these patients in the absence of clinical inflammation. CPPD crystals were observed in samples from patients with previous inflammatory episodes, but also in samples from patients who had never had arthritis. As crystals were found in all the samples studied, it would appear that after the crystals reach the joint cavity, periods free of crystals are rare, and the crystals stay in the joints without causing clinical symptoms (some of these patients had never suffered from arthritis, representing the so called lanthanic group. ${ }^{22}$ ) The regular presence of CPPD crystals in the joint cavity suggests either their slow clearance from the cavity, or constant shedding from joint deposits, mainly the cartilage, or both. It has been reported that detection of CPPD crystals can be intermittent when successive synovial fluid analyses are carried out in the same joint; ${ }^{23}$ if this is so, our results indicate that periods with crystals appear to be more common. Crystal shedding has been suggested as the mechanism for acute CPPD related $\operatorname{arthritis}^{24}$; however, 51 of our patients had crystals (often many) in knees in which inflammation had never occurred. Thus, although shedding of new crystals may indeed play a role in triggering joint inflammation; it does not necessarily result in joint inflammation.

Cells containing intracellular CPPD crystals were found in all synovial fluid samples, indicating that phagocytosis is a regular feature in these non-inflamed joints. Most of these cells were mononuclear, and often contained more than one crystal. The proportion of cells with intracellular crystals was rather high, and reached nearly one of every four cells counted. These data indicate that there is an active interaction between crystals and cells in these non-inflamed joints of patients with CPPD related arthropathy. Intracellular crystals were first described in inflamed joints in these arthropathies. Later on, phagocytosis of crystals was described in synovial fluid samples obtained from patients with osteoarthritis. ${ }^{25}$ In patients with gout, intracellular MSU crystals are also a common feature in synovial fluid samples obtained from asymptomatic joints.

Cell counts and the percentage of PMN cells provide relevant information about the degree of joint inflammation. Normal joints have low cell counts (fewer than 100 cells $/ \mu \mathrm{l}$ ). ${ }^{26}$ The mean cell count found here in non-inflamed joints was higher than the values reported for normal joints. In addition, synovial fluid samples from normal joints contain few PMN cells, usually none. ${ }^{27}$ As PMN leucocytes are not "resident" cells in the joint, their presence suggests inflammation. In our study, PMN cells were detected in all the samples, accounting for a mean of $16.8 \%$ of the cells. The increased cellularity in the synovial fluid and the presence of PMN leucocytes most probably indicate the presence of low degree inflammation in these clinically non-inflamed joints from patients with CPPD related arthropathy. Of interest, cell counts and the percentage of PMN leucocytes were similar in the knees of asymptomatic patients and in those with some

Table 1 Cell counts in patients with and without pain

\begin{tabular}{lll}
\hline & Pain group ( $\mathbf{n}=52)$ & Asymptomatic group ( $\mathbf{n}=22)$ \\
\hline Per cent cells with crystals & $23.7 \%(19.3$ to 28.0$)$ & $24.7 \%(16.0$ to 33.4$)$ \\
Cell count (cells $/ \mu$ ) & $338.1(225.8$ to 450.3$)$ & $215.0(105.8$ to 324.2$)$ \\
Per cent of PMN cells & $17.5 \%(14.2$ to 20.9$)$ & $15.0 \%(9.3$ to 20.6$)$ \\
\hline
\end{tabular}

Values are mean $(95 \%$ confidence interval).

PMN, polymorphonuclear. 
chronic pain, suggesting that pain was not related to the findings.

The identification of crystals in synovial fluid samples obtained during inflammatory episodes has been the definitive procedure for diagnosing CPPD deposition disease. In the absence of joint inflammation, criteria based on combinations of clinical and radiological data have been proposed to establish a possible or probable diagnosis. ${ }^{28}$ The regular presence of CPPD crystals in synovial fluid samples obtained from asymptomatic joints indicates that a definitive diagnosis of CPPD arthropathy can be made at any time if needed, as we have shown in the case of gout. ${ }^{29}$

\section{Conclusion}

Our results show that CPPD crystals are normally found in synovial fluid samples obtained from non-inflamed knees of patients with CPPD deposition disease. The regular presence of intracellular crystals confirms an interaction between crystals and cells in such joints, in the absence of clinical inflammation. The presence of mild subclinical inflammation is supported by the higher than normal cell count and by the presence of PMN cells. These findings are similar to those in gout.

\section{Authors' affiliation}

A Martínez Sanchis, E Pascual, Sección de Reumatología, Hospital General Universitario de Alicante, C/Pintor Baeza s/n, 03010 Alicante, Spain; martinez_agu@gra.es

\section{REFERENCES}

1 McCarty DJ, Kohn NN, Faires JS. The significance of calcium pyrophosphate crystals in the synovial fluid of arthritic patients: the "pseudogout syndrome". I. Clinical aspects. Ann Intern Med 1962;56:711-37.

2 Kohn NN, Hughes RE, McCarty DJ, Faires JS. The significance of calcium pyrophosphate crystals in the synovial fluid of arthritic patients: the "pseudogout syndrome". II. Identification of crystals. Ann Intern Med 1962;56:738-45.

3 McCarty DJ. Calcium pyrophosphate dihydrate crystal deposition disease. Arthritis Rheum 1976;19:275-86.

4 McCarty DJ, Phelps P, Pyenson J. Crystal-induced inflammation in canine joints. I. An experimental model with quantification of the host response. J Exp Med 1966; 124:99-114.

5 McCarty DJ. Crystal-induced inflammation of the joints. Annu Rev Med 1970;21:357-66.

6 Guerne PA, Terkeltaub R, Zuraw B, Lotz M. Inflammatory microcrystals stimulate interleukin- 6 production and secretion by human monocytes and synoviocytes. Arthritis Rheum 1989:32:1443-52.

7 Terkeltaub R, Zachariae C, Santoro D, Martin J, Peveri P, Matsushima K. Monocyte-derived neutrophil chemotactic factor/interleukin-8 is a potential mediator of crystal-induced inflammation. Arthritis Rheum 1991;34:894-903.

8 Roberge CJ, Grassi J, De Medicis R, Frobert Y, Lussier A, Naccache PH, et al. Crystal-neutrophil interactions lead to interleukin-1 synthesis. Agents Actions $1991 ; 34: 38-41$.
9 Hachicha M, Naccache PH, McColl SR. Inflammatory microcrystals differentially regulate the secretion of macrophage inflammatory protein 1 and interleukin 8 by human neutrophils: a possible mechanism of neutrophil recruitment to sites of inflammation in synovitis. J Exp Med 1995; 182:2019-25

10 Meng ZH, Hudson AP, Schumacher HR, Baker JF, Baker DG. Monosodium urate, hydroxyapatite, and calcium pyrophosphate crystals induce fumor necrosis factor-alpha expression in a mononuclear cell line. J Rheumatol 1997;24:2385-8.

11 Pascual E, Batlle-Gualda E, Martínez A, Rosas J, Vela P. Synovial fluid analysis for diagnosis of intercritical gout. Ann Intern Med 1999;131:756-9.

12 Li-Yu J, Clayburne G, Sieck M, Beutler A, Rull M, Eisner E, et al. Treatment of chronic gout. Can we determine when urate stores are depleted enough to prevent attacks of gout? J Rheumatol 2001;28:577-80.

13 Pascual E, Jovani V. A quantitative study of the phagocytosis of urate crystals in the synovial fluid of asymptomatic joints of patients with gout. $\mathrm{Br} J$ Rheumatol 1995;34:724-6.

14 Pascual E. Persistence of monosodium urate crystals, and low grade inflammation, in the synovial fluid of untreated gout. Arthritis Rheum $1991 ; 34: 141-5$.

15 Pascual E, Castellano JA. Treatment with colchicine decreases the white cell counts in the synovial fluid of asymptomatic knees which contain monosodium urate crystals. J Rheumatol 1992;19:600-3.

16 Ivorra J, Rosas J, Pascual E. Most calcium pyrophosphate crystals appear as non-birefringent. Ann Rheum Dis 1999;58:582-4.

17 Lumbreras B, Pascual E, Frasquet J, Gonzalez-Salinas J, Rodríguez E, Hernández-Aguado I. Analysis for crystals in synovial fluid: training of the analysts results in high consistency. Ann Rheum Dis 2005;64:612-15.

18 Hasselbacher P. Variation in synovial fluid analysis by hospital laboratories. Arthritis Rheum 1987;30:637-42.

19 Schumacher HR, Sieck MS, Rothfuss S, Clayburne GM, Baumgarten DF, Mochan BS, et al. Reproducibility of synovial fluid analysis. Arthritis Rheum 1986;29:770-4.

20 Gordon C, Swan A, Dieppe P. Detection of crystals in synovial fluid by light microscopy: sensitivity and reliability. Ann Rheum Dis 1989;48:737-42.

21 Reginato AJ, Maldonado I, Reginato AM, Falasca GF, O'Connor CR. Supravital staining of synovial fluid with Testsimplets. Diagn Cytopathol 1992;8: 147-52.

22 Ryan LM, McCarty DJ. Calcium pyrophosphate crystal deposition disease pseudogout and articular chondrocalcinosis. In: Koopman WJ, eds. Arthritis and allied conditions. A textbook of rheumatology. Baltimore: Williams \& Wilkins, 1997:2103-25

23 Hamilton E, Pattrick M, Hornby J, Derrick G, Doherty M. Synovial fluid calcium pyrophosphate dihydrate crystals and alizarin red positivity: analysis of 3000 samples. Br J Rheumatol 1990;29:101-4.

24 Bennett RM, Lehr JR, McCarty DJ. Crystal shedding and acute pseudogout: an hypothesis based on a therapeutic failure. Arthritis Rheum 1976;19:93-7.

25 Gibilisco PA, Schumacher HR, Hollander JL, Soper KA. Synovial fluid crystals in osteoarthritis. Arthritis Rheum 1985;28:511-15.

26 Pascual E. Analysis of synovial fluid from healthy knees. Comparison with fluid from asymptomatic knees in RA, SLE, and gout. Arthritis Rheum 1992;35:S310.

27 McCarty DJ. Synovial fluid. In: Koopman WJ, eds. Arthritis and allied conditions. A textbook of rheumatology. Baltimore: Williams \& Wilkins, 1997:81-102.

28 Ryan LM, McCarty DJ. Calcium pyrophosphate crystal deposition disease pseudogout, and articular chondrocalcinosis. In: Koopman WJ, eds. Arthritis and allied conditions. A textbook of rheumatology. Baltimore: Williams \& Wilkins, 1997:2103-25.

29 Pascual E, Batlle-Gualda E, Martinez A, Rosas J, Vela P. Synovial fluid analysis for diagnosis of intercritical gout. Ann Intern Med 1999;131:756-9. 